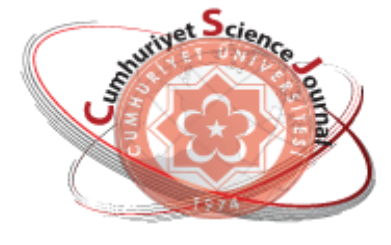

e-ISSN: 2587-246X

ISSN: $2587-2680$

\section{Cumbaniy at Seience Journal $\cos$}

Cumhuriyet Sci. J., Vol.40-2(2019) 518-520

\title{
Examination of the Effect of Different Projectile Geometries on the Performance of Reluctance Launcher Using 3D Finite Element Analysis

\author{
Vekil SARI ${ }^{1, *}$ (D) Ferhat DALBADAN ${ }^{2}$ (D)
} \\ ${ }^{1}$ Department of Electrical and Electronics Engineering, Faculty of Engineering, Cumhuriyet University, 58140, Sivas/ Turkey \\ ${ }^{2}$ Department of Electrical and Electronics Engineering, Faculty of Engineering, Erciyes University, 38039, Kayseri/ Turkey
}

Received: 09.02.2018; Accepted: 19.04.2019

http://dx.doi.org/10.17776/csj.392910

\begin{abstract}
In this paper, the 3D model of a reluctance electromagnetic launcher was implemented using Maxwell program. The effect of the different projectile geometries was examined via the model. The projectile geometry with the highest velocity was determined. After constructing 3D model of the launcher, projectiles with different geometries were built and finally various projectiles with different geometries were analyzed. As a result, it was determined that the tubular projectile with $4 \mathrm{~mm}$ radius hole was the fastest among the tubular projectiles. Among the projectiles with notches, the projectile with 4 notches was launched faster than the others when the parameter was the number of notches, and the projectile with $0.5 \mathrm{~mm}$ notch radius was faster than the others when the parameter was the notch radius. In this paper, the highest velocity was reached the tubular projectile with $4 \mathrm{~mm}$ radius that was built with the 1050 material. The value of this velocity was $24.12 \mathrm{~m} / \mathrm{s}$.
\end{abstract}

Keywords: Coilguns, linear accelerators, electromagnetic launching, finite elements analysis.

\section{Boyutlu Sonlu Elemanlar Analizi Kullanılarak Farklı Mermi Geometrilerinin Relüktans Fırlatıcının Performansına Etkisinin İncelenmesi}

Özet. Bu çalışmada, relüktans elektromanyetik firlatıcının 3 boyutlu modeli Maxwell programı kullanılarak oluşturulmuştur. Farklı mermi geometrilerinin etkisi model vasıtasıyla incelenmiştir. En yüksek hıza sahip mermi geometrisi belirlenmiştir. Fırlatıcının 3 boyutlu modeli oluşturulduktan sonra, farklı geometrilere ait mermiler oluşturulmuş ve analizler yapılmıştır. Bu analizlerin sonucunda boru tipi mermilerde; iç boşluk yarıçapı 4 mm olan merminin diğer boru tipi mermilere göre daha yüksek hızla firlatıldı̆̆ı tespit edilmiştir. Çentikli mermilerde ise çentik sayısına göre; 4 çentikli merminin diğer çentik sayılarına sahip mermilerden daha hızlı firlatıldığı, çentik yarıçapına göre; çentik yarıçapı $0.5 \mathrm{~mm}$ olan çentikli merminin diğer mermilerden daha hızlı olduğu tespit edilmiştir. Bu çalışmada en yüksek hıza iç boşluk yarıçap1 4 mm olan 1050 den yapılmış boru tipi mermide ulaşılmıştır. Bu hız değeri $24.12 \mathrm{~m} / \mathrm{sn}$ 'dir.

Anahtar Kelimeler: Bobin silahı, lineer hılandırıcı, elektromanyetik firlatma, sonlu elemanlar analizi. 


\section{INTRODUCTION}

Electromagnetic launchers were developed due to many disadvantages and velocity limitations of chemical launchers [1]. The idea of launching projectiles using electricity is not new. It's been known since 1846. However, the most significant improvements have taken place in the past few decades [2]. Electromagnetic launchers are used in many areas, but mostly in military and space applications [3]. The interest in electromagnetic launchers have increased significantly in the past few years.

Electromagnetic launchers can be divided into two categories; electromagnetic rail guns and electromagnetic coil guns [4]. Rail gun consists of two parallel metal rails and an armature that can slide on these rails. They are convenient for launching large projectiles. When the voltage was applied to the rails, the armature completes the cycle and a current flows on the armature. A force is exerted on the armature which resides in the magnetic field induced by the current flowing through the rails. Armature moves with the effect of this force. The moving armature launches the projectile in front of it [5]. The structure and the operation principle of the coil gun are more complex. It consists of a cylindrical armature, one or more coils wounded to this cylinder and a projectile to be launched [6]. In coil guns, there is almost no friction between the muzzle and the projectile, thus the acceleration system is not damaged [7].

The velocity obtained with the rail gun is higher than the velocity obtained with the coil gun. However, the required excitation current is much higher [8]. Additionally, rail guns have problems due to melting and erosion [9]. The efficiency of the coil gun is higher than the rail gun because of the strong magnetic coupling between the coils and the projectile $[10,11]$.

Electromagnetic coil guns can be divided into two categories according to their operation principles. These are induction-type electromagnetic launchers (IEML) and reluctance electromagnetic launchers (REML). In IEMLs, the non-magnetic projectile in the middle of the coil is accelerated and launched $[12,13]$. The operation principle of the REML depends on the reluctance theory. The magnetic field induced on the coils attracts and pulls the ferromagnetic projectile towards the center of the coil [14-16]. REML have many advantages such as easy control, simple structure and high reliability when compared with other launchers [17].

In REMLs, ferromagnetic projectiles are used and their BH characteristics are non-linear [18]. Therefore, the analysis of these launchers is difficult. Finite Element Analysis (FEA) is usually preferred for the analysis of these launchers [1923].

In a previous study, different projectile geometries for REMLs were studied and, projectiles with notches and projectiles with tail fins were examined [17]. A five-stage REML was built to launch those projectiles. For each driving coil, capacitance of the capacitor banks were $450 \mu \mathrm{F}$ and the charge voltage was $600 \mathrm{~V}$. As a result, higher launching efficiency was obtained with projectile with notches. The velocity difference between projectile with notches and normal projectiles is small. But in this paper, the highest velocity obtained using projectiles with notches increased $19 \%$ according to the highest velocity obtained using normal projectiles. This may be due to projectile material or launcher geometry.

In another study, projectiles constructed using three different materials were studied and 2, 8, and 16 slits were cut on the projectiles [24]. It was expressed that as the number of slits increased, the projectile velocity would increase, and the experiments proved this result. Additionally, it was determined that the efficiency usually tends to increase when the number of slits increase but the velocity decreased in one of the projectiles of a specific material. In this paper, the number of notches is 2,4 , and 8 respectively. The velocity increased until the number of notches exceeded 4 , 
thus it decreased for the projectiles with 8 notches. This is because the projectile material decreases when the number of notches increases. Because the flux cannot flow from the material.

Before implementing electromagnetic systems, the model of the system is generally constructed using electromagnetic analysis software such as Maxwell, Magnet, and Flux and then information is gathered by analyzing this model. In this study, Maxwell is used to create and analyze the 3D model of a single-coil REML. In Maxwell, the model of a system can be create in 2D or 3D [25]. 2D models are easier to build and the time required for the analysis is short. However, the 2D model does not cover the three-dimensional effects [26].

In previous studies, projectiles with notches were examined, but tubular projectiles were not examined. In this paper, the comparison of the projectiles with notches and tubular projectiles. In this paper, 3D model of a REML was used and more accurate results were obtained by including the three-dimensional effects. Then projectiles with different geometries were constructed and the launching velocity of the system was examined. The studied projectiles with different geometries are tubular projectiles and projectiles with notches. The interiors of the projectiles were drilled 1 to 5 mm-radius holes while tubular projectiles were built. The numbers of notches are 2, 4, and 8 for the projectiles with notches and the radius of the notches are $0.25,0.5$, and $1 \mathrm{~mm}$. After the 3D model of the launcher system was constructed, the launcher model was analyzed. As a result, it was determined that the tubular projectile with $4 \mathrm{~mm}$ radius hole was the fastest among the tubular projectiles. Among the projectiles with notches, the projectile with 4 notches was launched faster than the others when the parameter was the number of notches, and the projectile with $0.5 \mathrm{~mm}$ notch radius was faster than the others when the parameter was the notch radius.

\section{THEORY OF RELUCTANCE ELECTROMAGNETIC LAUNCHERS}

A reluctance electromagnetic launcher consists of a cylindrical tube and a coil wound around this tube. The tube used as the muzzle should not be constructed by using a magnetic material and the projectile must be constructed using ferromagnetic material. When a current flows through the coil, a magnetic field is induced around the coil. The magnetic field applies a reluctance force to the ferromagnetic projectile inside the tube and it pulls the projectile through the center of the tube. In REMLs, the projectile is pulled to the center of the coil, it is not pushed. The current of the coil must be turned off when the projectile reaches the center, or it will be pulled to the center again. This may decelerate the projectile or prevent the projectile to be launched. This should be in mind while constructing a REML. Sensors should be used to detect if the projectile reached the center.

If the REML consists of multiple coils, each coil will fasten the projectile a bit more. When the projectile gets into the attraction area of the next coil, this coil should be energized and when the projectile reaches the center of this coil, the current should be turned off. The damping time of the current flowing through the coils and the energy in the coils affect the efficiency of the launcher considerably. The timing should be adjusted using sensors.

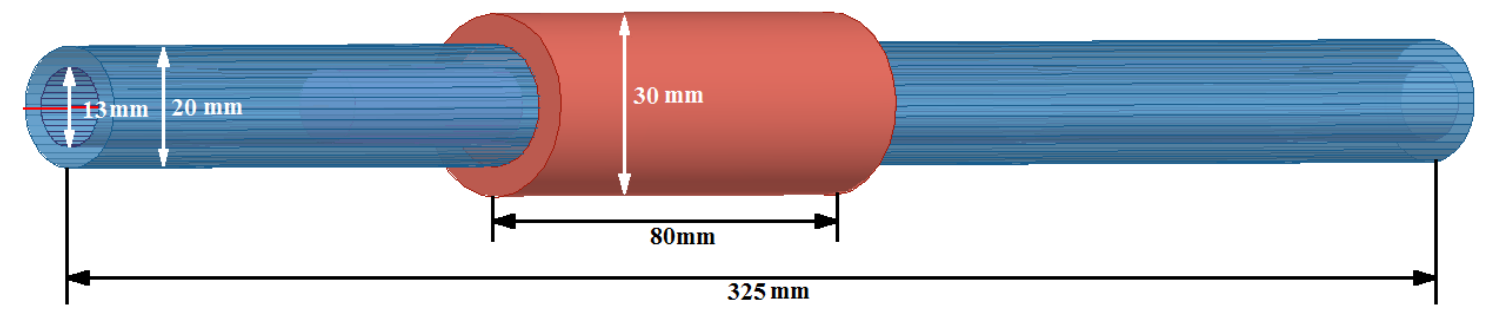

Figure 1. View of the reluctance electromagnetic launcher. 
Figure 1 shows a single-coil launcher that was modelled. Launchers convert the electrical energy into the magnetic energy first, and then it converts the magnetic energy to the mechanical energy. During this conversion, there will be electrical, magnetic and mechanical losses [27].

\section{3D ANALYSIS OF RELUCTANCE LAUNCHER}

In this study, FEA of a single-coil REML was realized using Maxwell software. 3D model of the launcher was constructed for FEA. The geometries of the projectiles were changed after the model was constructed and then the projectile geometry with the highest velocity was determined. The 3D Maxwell model of the launcher is shown in Figure 2. The magnetic flux density shown in Figure 3 is nearly $1.4 \mathrm{~T}$ inside the coil and $0.7 \mathrm{~T}$ at the edge of the coil.

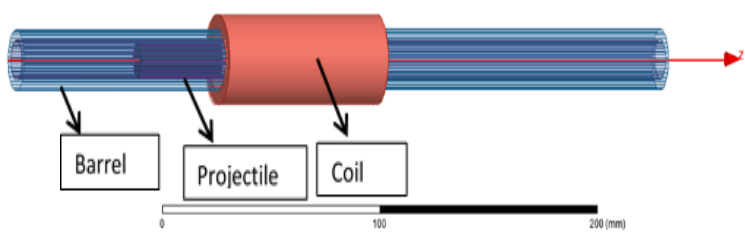

Figure 2. Maxwell model of the launcher.

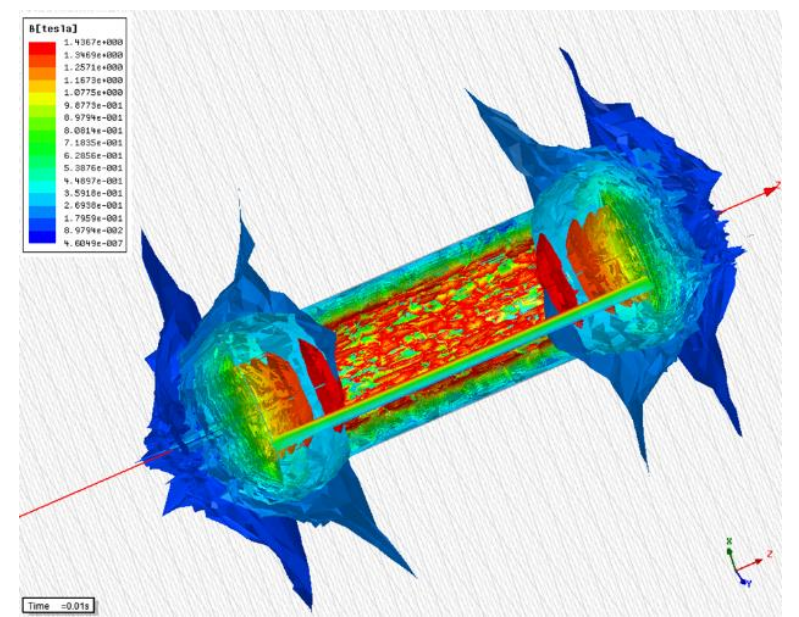

Figure 3. Magnetic flux density.

In this paper, the launching of $4 \mathrm{~cm}$-length and 6.25 mm-radius projectiles constructed using different geometries and different materials such as 1020 , 1050 , and 12L14 was studied. BH characteristics of these materials are shown in Figure 4 [28].

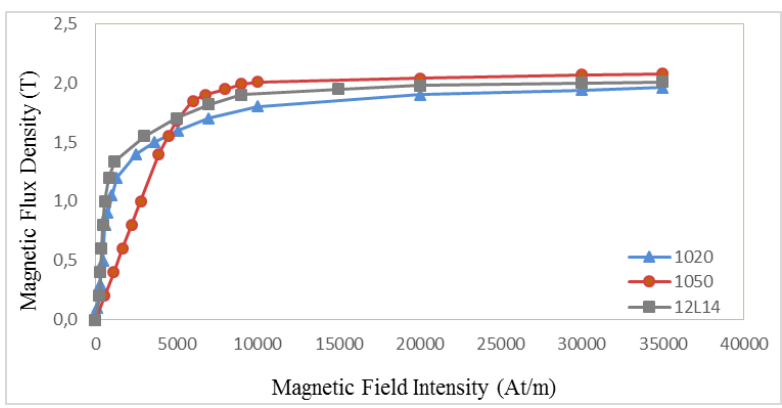

Figure 4. BH characteristics of the materials.

Table 1. Velocities of the projectiles with unmodified geometries.

\begin{tabular}{|c|c|c|c|}
\hline \multicolumn{4}{|c|}{ Projectiles with unmodified geometry } \\
\hline \multicolumn{3}{|c|}{ Velocity $(\mathrm{m} / \mathrm{s})$} & Weight \\
\hline 1020 & 1050 & 12L14 & (gr.) \\
\hline 18.78 & 19.24 & 19.01 & 38.445 \\
\hline
\end{tabular}

Then the geometry of the projectile was modified and tubular projectiles were constructed where the outer radius $(\mathrm{r} 1)$ of the projectile is still $6.25 \mathrm{~mm}$, but the interior was drilled for having a hole with radius 1 to $5 \mathrm{~mm}(\mathrm{r} 2)$. Tubular projectile is shown in Figure 5. Table 2 shows the velocities of each projectile.

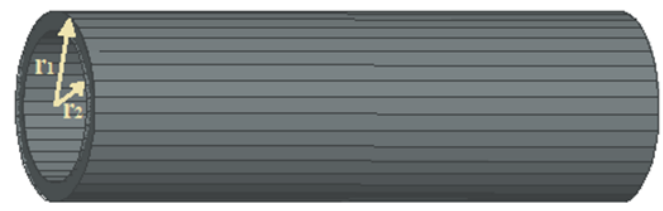

Figure 5. View of the tubular projectile.

Table 2. Velocities of the tubular projectiles

\begin{tabular}{ccccc}
\hline \multicolumn{5}{c}{ Tubular projectiles } \\
\cline { 2 - 5 } $\begin{array}{c}\text { Inner hole } \\
\text { radius } \mathrm{r}_{2} \\
\text { (mm.) }\end{array}$ & 1020 & 1050 & $12 \mathrm{~L} 14$ & Welocity $(\mathrm{m} / \mathrm{s})$ \\
(gr.)
\end{tabular}




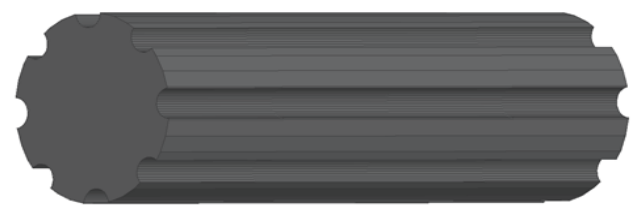

Figure 6. View of projectile with notch. Then the projectile geometry with notches was considered and 2, 4, and 8 notches were constructed at the side surfaces of the projectiles. Notches were circular-shaped. The radius of the constructed notches are $0.25,0.5$, and $1 \mathrm{~mm}$, respectively. Figure 6 shows the projectile with notches. Table 3 shows the velocities of the projectiles with notches.

Table 3. Velocity results of projectiles with notch.

\begin{tabular}{|c|c|c|c|c|c|}
\hline \multicolumn{6}{|c|}{ Projectiles with notch } \\
\hline \multirow{2}{*}{$\begin{array}{l}\text { Notch } \\
\text { radius } \\
\text { (mm.) }\end{array}$} & \multirow{2}{*}{$\begin{array}{l}\text { Number } \\
\text { of } \\
\text { notches }\end{array}$} & \multicolumn{3}{|c|}{ Velocity $(\mathrm{m} / \mathrm{s})$} & \multirow{2}{*}{$\begin{array}{c}\text { Weigh } \\
\text { (gr.) }\end{array}$} \\
\hline & & 1020 & 1050 & $12 \mathrm{~L} 14$ & \\
\hline \multirow{3}{*}{0.25} & 2 & 19.86 & 20.36 & 20.08 & 38.387 \\
\hline & 4 & 21.3 & 21.87 & 21.6 & 38.329 \\
\hline & 8 & 20.99 & 21.44 & 21.4 & 38.214 \\
\hline \multirow{3}{*}{0.5} & 2 & 20.04 & 21.24 & 20.85 & 38.213 \\
\hline & 4 & 22.52 & 22.91 & 22.7 & 37.981 \\
\hline & 8 & 20.64 & 21.01 & 20.72 & 37.511 \\
\hline \multirow{3}{*}{1} & 2 & 21.57 & 21.92 & 21.79 & 37.516 \\
\hline & 4 & 21 & 21.14 & 21.04 & 36.586 \\
\hline & 8 & 10.14 & 10.29 & 10.2 & 34.726 \\
\hline
\end{tabular}

The highest velocity of the projectiles with unchanged geometry is $19.24 \mathrm{~m} / \mathrm{s}$. This velocity obtained with 1050 projectile. The 1020 projectile has the lowest velocity. When the relative permeability of the projectile material increases, the velocity increases too. The same result can be obtained when the velocities of tubular projectiles in Table 2 are analyzed. The velocities of all projectiles built with 1050 material are higher than the others, then comes 12L14 and 1020 projectiles respectively. When the velocities of the projectiles with unmodified geometry and tubular projectiles are compared. It can be seen that tubular projectiles are faster. When the interior hole radius is $1 \mathrm{~mm}$, projectile velocities of all material types are higher. The velocity increases until the interior hole radius exceeds $4 \mathrm{~mm}$, and it decreases when the interior hole radius is $5 \mathrm{~mm}$. In tubular projectiles, projectiles with $4 \mathrm{~mm}$ interior hole radius are faster. When the interior hole radius is less or greater than
$4 \mathrm{~mm}$, the projectile velocity decreases. The highest velocity in tubular projectiles is $24.12 \mathrm{~m} / \mathrm{s}$. It is obtained with the projectile of 1050 material and $4 \mathrm{~mm}$ interior hole radius.

When the velocity results of projectiles with notches (Table 3) are interpreted, it is detected that the projectiles with the highest velocity are built with 1050 material, then comes 12L14 and 1020, respectively. If the velocity results are examined for number of notches and notch radius, we see that the velocity of the projectiles with 0.25 and $0.5 \mathrm{~mm}$ notch radius increases and the velocity of the projectile with $1 \mathrm{~mm}$ notch radius decreases when number of notches increases from 2 to 4 . When the number of notches increases from 4 to 8 , velocities of all the projectiles decrease. Higher velocities are obtained when the number of notches is 4 . When the notch radius increases from 0.25 to $0.5 \mathrm{~mm}$, velocity of projectiles with 2 notches increases while velocities of projectiles with 4 and 8 notches decrease. The highest velocity measured using projectiles with notches is $22.91 \mathrm{~m} / \mathrm{s}$. It is obtained with the projectile with 4 notches built with 1050 material and having a radius of $0.5 \mathrm{~mm}$.

In this paper, the highest velocity value measured with projectiles having different geometries is $24.12 \mathrm{~m} / \mathrm{s}$. This value was obtained with the projectile of 1050 material, $4 \mathrm{~cm}$-length, $6.25 \mathrm{~mm}$ outer radius and $4 \mathrm{~mm}$ inner hole radius. Therefore, the projectile with the highest velocity was analyzed. Figure 7 shows the magnetic flux density when the projectile is in the coil. Magnetic flux density is around $20 \mathrm{~T}$ at a very small part of the projectile, around $10-15 \mathrm{~T}$ at some parts, and around 3-4 $\mathrm{T}$ at most parts. Magnetic flux density is very high, but occurs in a very short time (milliseconds). 


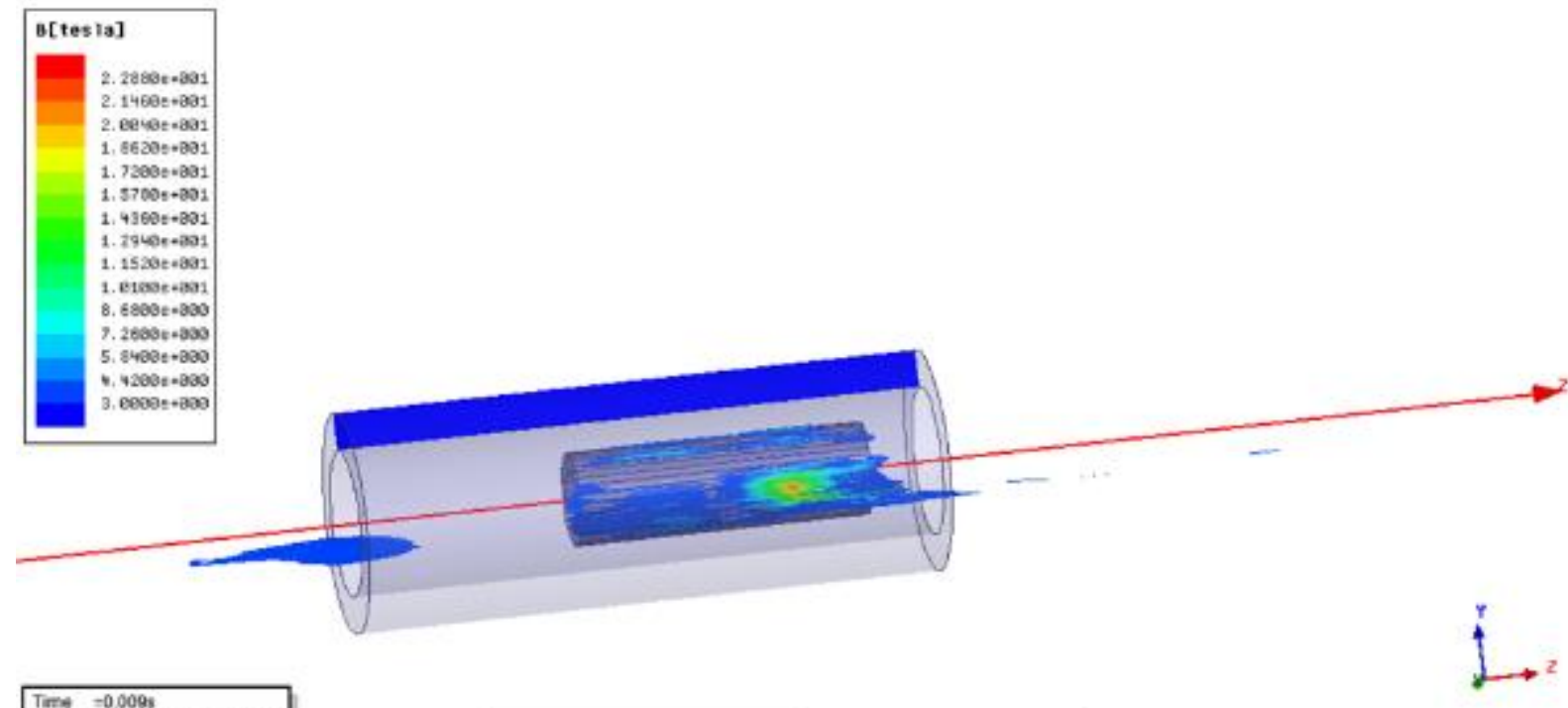

$\operatorname{Tims}_{\text {Speed }}=0.009 \mathrm{~s}$

Poutton $=31.013060 \mathrm{~mm}-10$

Figure 7. Magnetic flux density when the projectile is in the coil.

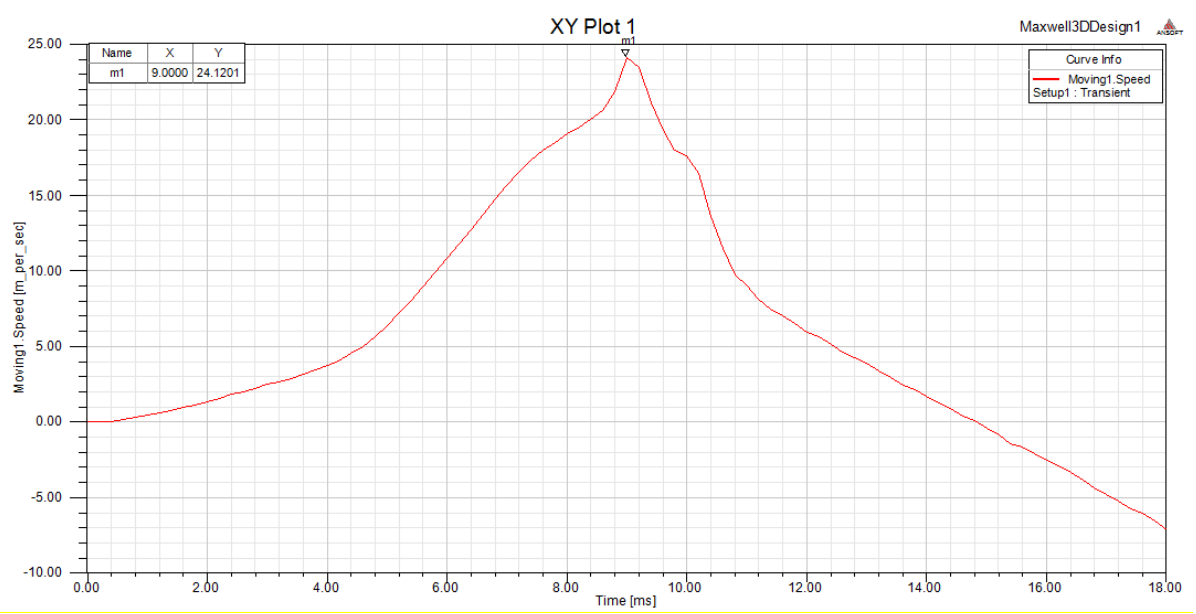

Figure 8. Velocity change with time.

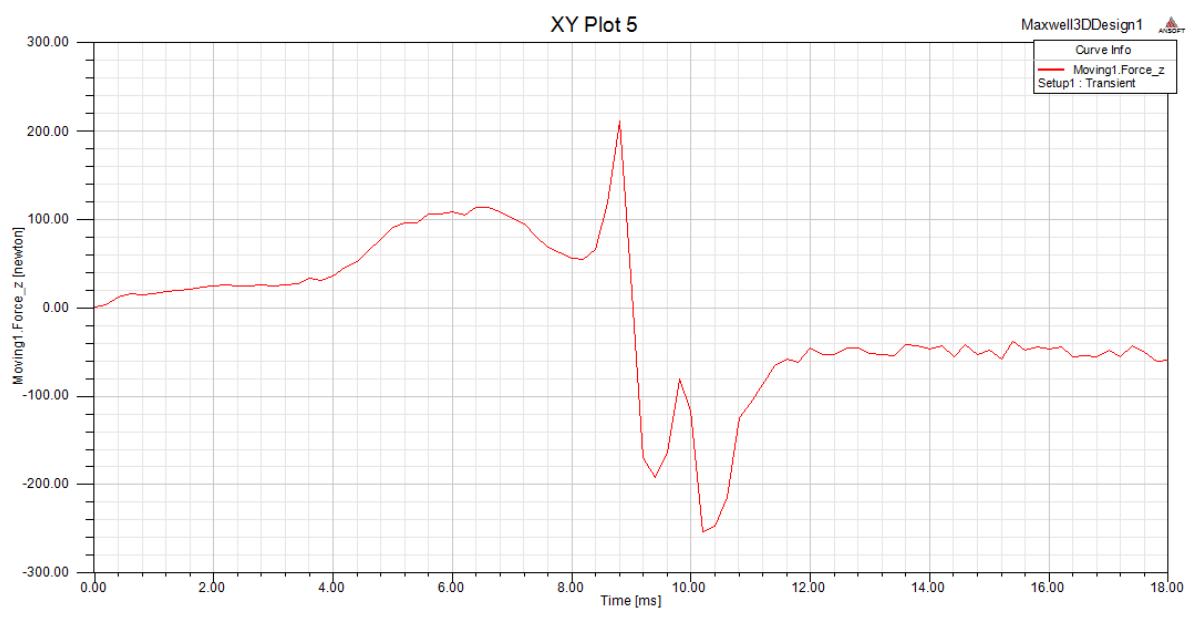


Figure 9. The change of force applied to the projectile.

Figure 8 shows the velocity-time graph of the projectile. The projectile reaches the highest velocity at $9 \mathrm{~ms}$. The current flowing through the coil must be turned off when the projectile reaches the maximum velocity because it should not be pulled back to the center.

Figure 9 shows the force applied to the projectile in time. A forward direction force is applied to the projectile until $9 \mathrm{~ms}$ and the projectile is moved through the center of the coil. After $9 \mathrm{~ms}$ a backward force is applied and it is moved to the center of the coil again.

\section{DISCUSSION}

According to the analysis results, in consistence with the previous studies[20, 24], the velocity of the projectiles is proportional to the relative permeability of the projectile materials. 1050 has the highest relative permeability. Thus, the projectiles built with 1050 material have the highest velocities and then comes 12L14 and 1020, respectively. When the projectile is drilled to construct a tubular projectile, the velocity increases. The tubular projectile with $4 \mathrm{~mm}$ radius hole was the fastest among the tubular projectiles. Among the projectiles with notches, the projectile with 4 notches was launched faster than the others when the parameter was the number of notches, and the projectile with $0.5 \mathrm{~mm}$ notch radius was faster than the others when the parameter was the notch radius.

When the velocity results of the projectiles with notches are examined, it can be seen that the velocity increases until the number of notches increases up to 4, then it decreases. When the notch radius increases up to $0.5 \mathrm{~mm}$, the velocity of the projectiles increases and then it decreases. The highest velocity of projectiles with notches is obtained using the projectile with 4 notches having a radius of $0.5 \mathrm{~mm}$.

\section{CONCLUSION}

In previous studies, projectiles with notches were examined, but tubular projectiles were not examined. In this paper, the comparison of the projectiles with notches and tubular projectiles. In this paper, the 3D model of a REML was implemented and the effect of changing the projectile geometries on the projectile velocities was examined. The projectile geometry with the highest velocity was determined. In consistence with the results of the previous works, the velocity of the projectiles increase when the relative permeability of the projectile materials increases.

It is detected that the velocity increases when the projectile is drilled to construct a tubular projectile, and the velocity is at its highest value for tubular projectiles with $4 \mathrm{~mm}$ radius hole. It is seen that the velocity increases when the projectile is notched. The maximum velocity is reached with the projectile with 4 notches and a radius of $0.5 \mathrm{~mm}$. The maximum velocity of the projectiles with notches is $19 \%$ more than the maximum velocity of the projectiles without notches, while the maximum velocity of tubular projectiles is $25.36 \%$ more than the maximum velocity of the projectiles which are not tubular.

When the velocity results of projectiles with notches are examined, it can be seen that the velocity increases until the number of notches increases up to 4 , then it decreases. When the notch radius increases up to $0.5 \mathrm{~mm}$, the velocity of the projectiles increases and then it decreases. The highest velocity of projectiles with notches is obtained with the 4 projectile with notches having a radius of $0.5 \mathrm{~mm}$.

\section{ACKNOWLEDGMENTS}

Thanks to Erciyes University Scientific Research Project (BAP) Department who supported this work under the project number FBD-10-3313. 


\section{REFERENCES}

[1] Fair H. D., Electromagnetic propulsion: A new initiative, IEEE Transactions on Magnetics, 181 (1965) 4-6.

[2] Mcnab I. R., Stefani F., Crawford M., Erengil M., Persad C. and Satapathy S., Development of a naval railgun, IEEE Transactions on Magnetics, 41-1 (2005) 206-210.

[3] Bresie D. A. and Andrews J. A., Design of a reluctance accelerator, IEEE Transactions on Magnetics, $27-1$ (1991) 623-627.

[4] He J., Levi E., Zabar Z. and Birenbaum L., Concerning the design of capacitively driven induction coil guns, IEEE Transactions on Plasma Science, 17-3 (1989) 429-438.

[5] Bayati M. S., Keshtkar A. and Gharib L., Analyzing the near and far field using finite difference and finite element method, IEEE Transactions on Plasma Science, 41-5 (2013) 1398-1402.

[6] Marder B., A coilgun design primer, IEEE Transactions on Magnetics, 29-1 (1993) 701705.

[7] Kim S. W., Jung H. K. and Hahn S. Y., An optimal design of capacitor driven coilgun, IEEE Transactions on Magnetics, 30-2 (1994) 207-211.

[8] Waindok A. and Mazur G., Mutual inductances in a mathematical model of the three-stage reluctance accelerator, 3rd International Students Conf. on Electrodynamics and Mechatronics, Opole, Poland, (2011) 115-118.

[9] Lv Q., Li Z., Xie S., Zhang Q., Zhao K. and Xiang H., A practical electromagnetic launcher concept-part I: Primary structure design and armature optimal simulation, 16th International Symposium on Electromagnetic Launch Technology, Beijing, China, (2012) 1-5.

[10] Hou Y., Liu Z., Yang L., Shen Z., Ouyang J. and Yang D., Analysis of back electromotive force in RCEML, 17th International Symposium on Electromagnetic Launch Technology, California, USA, (2014) 1-6.

[11] Yadong Z., Ying W. and Jiangjun R., Capacitordriven coil-gun scaling relationships, IEEE Transactions on Plasma Science, 39-1 (2011)
220-224.

[12] He J. L., Zabar Z., Levi E. and Birenbaum L., Transient performance of linear induction launchers fed by generators and by capacitor banks, IEEE Transactions on Magnetics, 27-1 (1991) 585-590.

[13] Korkmaz F., Topaloğlu I. and Gurbuz R., Simulink model of vector controlled linear induction motor with end effect for electromagnetic launcher system, Elektronika ir Elektrotechnika, 20-1 (2014) 29-32.

[14] Waindok A. and Mazur G., A mathematical and physical models of the three-stage reluctance accelerator, 2nd International Students Conference on Electrodynamic and Mechatronics, Gora Sw. Anny, Poland, (2009) 29-30.

[15] Zhiyuan L., Youtian L., Xueping M., Hongjun $X$. and Shumei C., Dynamic Research of MultiStage Reluctance Coil Gun, 17th International Symposium on Electromagnetic Launch Technology, San Diego, California, (2014) 1-4.

[16] Cooper L. M., Vancleef A. R., Bristoll B. T. and Bartlett P. A., Reluctance accelerator efficiency optimization via pulse shaping, IEEE Access, 2 (2014) 1143-1148.

[17] Xiang H., Lei B., Li Z. and Zhao K., Design and experiment of reluctance electromagnetic launcher with new-style armature, IEEE Transactions on Plasma Science, 41-5 (2013) 1066-1069.

[18] Barhoumi E. M., Hajji M. and Salah B. B., Design of a double-stator linear switched reluctance motor for shunting railway channels, Turkish Journal of Electrical Engineering and Computer Sciences, 22 (2014) 302-314.

[19] Kalender O., The optimization of launching a bullet using electromagnetic energy, Ph.D. thesis, Gazi University, Ankara, Turkey, (2005).

[20] Hou Y., Liu Z., Ouyang J. M. and Yang D., Parameter settings of the projectile of the coil electromagnetic launcher, 16th International Symposium on Electromagnetic Launch Technology, Beijing, China, (2012) 1-4.

[21] Chang J. H., Becker E. B. and Driga M. D., Coaxial electromagnetic launcher calculations using FE-BE method and hybrid potentials, 
IEEE Transactions on Magnetics, 29-1 (1993) 655-660.

[22] Chaowei Z., Pengshu D., Xiaojun D., Sanqun L., Zhiyuan L. and Guanghui Z., Analysis of reluctance coil launcher performance using coupled field-circuit method, International Conference on Electrical Machines and Systems, Wuhan, China, (2008) 4049-4052.

[23] Tarvydas P., Edge finite elements for 3D electromagnetic field modeling, Elektronika ir Elektrotechnika, 76-4 (2007) 29-32.

[24] Barrera T. and Beard R., Exploration and verification analysis of a linear reluctance accelerator, 17th International Symposium on Electromagnetic Launch Technology, California, USA, (2014) 1-6.

[25] Sveikata J., Tarvydas P. and Noreika A., Electric circuit analysis using finite element modeling, Elektronika ir Elektrotechnika, 63-7 (2005) 31-34.

[26] Michaelides A. M. and Pollock C., Effect of end core flux on the performance of the switched reluctance motor, IEE Proceedings - Electric Power Applications, 141-6 (1994) 308-316.

[27] Sen P. C., Principles of Electric Machines and Power Electronics. Singapore: John Wiley \& Sons, 1989; pp 101-104.

[28] Daldaban F. and Sari V., Analysis of a reluctance launcher by finite elements method, Journal of the Faculty of Engineering and Architecture of Gazi University, 30-4 (2015) 605-614. 